\title{
Moda rápida na indústria calçadista: Intervenção setorial no arranjo produtivo de Nova Serrana
}

\author{
Fast fashion in the footwear industry: Sector intervention in the \\ productive network of Nova Serrana
}

\author{
Giancarlo Medeiros Pereira ${ }^{1}$ \\ Miriam Borchardt ${ }^{1}$ \\ Miguel Afonso Sellitto ${ }^{1}$
}

\begin{abstract}
Resumo: Em 2008, fabricantes de calçados da região de Nova Serrana juntamente com seus fornecedores de insumos articularam uma intervenção setorial destinada a aumentar a diversidade da oferta na cadeia de suprimentos, acelerar o desenvolvimento de novos produtos e reduzir os custos dos insumos. A despeito do interesse das partes, a intervenção não produziu os resultados desejados. Este artigo busca entender os motivos que bloquearam tais objetivos. Foram estudados quinze fabricantes de calçados e quinze fornecedores de insumos. O método de pesquisa foi o estudo de caso múltiplo. Em sessões de grupos focados com os empresários, foi construída uma estrutura de construtos e variáveis que desvelou a inter-relação entre a flexibilidade de suprimento e o desenvolvimento de produtos. Os achados sugerem que a demanda por exclusividade de insumos, imposta pelos grandes fabricantes de calçados, a possibilidade de conflito com os representantes dos grandes e médios fornecedores de insumos, o receio de cópia das criações, a desatenção a demandas locais e o desempenho insatisfatório em entregas causaram o insucesso da intervenção.
\end{abstract}

Palavras-chave: Gestão da cadeia de suprimentos. Cadeias produtivas. Arranjos produtivos locais. Logística. Clusters.

\begin{abstract}
In 2008, shoe manufacturers in the region of Nova Serrana, along with their input suppliers, articulated a sectoral intervention aimed at increasing the diversity of the supply chain, accelerating new product development, and reducing input costs. Despite the interest of the actors, the intervention did not produce the desired results. This article seeks to understand the reasons that blocked these objectives. We studied fifteen footwear manufacturers and fifteen suppliers. The research method was the multiple case studies. In focus group sessions with business owners, we built a framework of constructs and variables that revealed the relationship between the flexibility of supply and product development. The findings suggest that the demand for exclusivity of supplies imposed by the major footwear manufacturers, the possibility of conflict with the representatives of large and medium-sized suppliers, the fear of copy creation, the inattention to local demands and unsatisfactory performance in deliveries caused the failure of this intervention.
\end{abstract}

Keywords: Supply Chain Management. Productive systems. Local productive networks. Logistics. Clusters.

\section{Introdução}

O mercado de moda denominado fast fashion (moda rápida ou modinha) tem como característica grande número de criações altamente diferenciadas, porém com curto ciclo de vida, em geral, poucas semanas. Tamanha diferenciação acarreta incerteza no cenário de negócios, tanto na demanda como no suprimento (CARO; GALLIEN, 2012). A incerteza decorre principalmente da incapacidade de se usarem fatos passados como base para previsões, pois as condições ambientais passadas dificilmente se reproduzem. A incerteza em negócios, portanto, associa-se à ausência de informação segura sobre o futuro (LOMBARDI; BRITO, 2010).
Os efeitos da incerteza podem ser mitigados por uma estratégia articulada de operação em cadeia de suprimentos (PAULRAJ; CHEN, 2007). Cadeias de suprimentos são formadas sempre que as empresas não possuam, individualmente, todas as capacitações e recursos de que necessitam. Por meio das relações de colaboração que surgem na cadeia, novas habilidades e competências podem ser adquiridas pelas empresas (RODRIGUES; SELLITTO, 2008).

A literatura apresenta alternativas para lidar com a incerteza em cadeias de suprimentos (CHILDERHOUSE; TOWILL, 2004, BHATNAGAR; SOHAL, 2005; SAWHNEY, 2006, AVITTATHUR;

\footnotetext{
${ }^{1}$ Programa de Pós-graduação em Engenharia de Produção e Sistemas - PPGEPS, Universidade do Vale do Rio dos Sinos - UNISINOS, CEP 93022-000, São Leopoldo, RS, Brasil, e-mail: gian@unisinos.br; miriamb@unisinos.br; sellitto@unisinos.br
}

Recebido em 10/5/2013 — Aceito em 7/5/2014

Suporte financeiro: $\mathrm{CNPq}$. 
SWAMIDASS, 2007; STEVENSON; SPRING, 2007). Uma destas alternativas é a flexibilidade na produção. Estudos têm revelado que a lucratividade cresce quando se alinham estratégias de flexibilidade entre a empresa focal e seus fornecedores, articulando as atividades de cadeias de suprimentos (AVITTATHUR; SWAMIDASS, 2007).

A gestão da cadeia de suprimentos (SCM - Supply Chain Management) pode e deve incluir o desenvolvimento de novos produtos (NPD - New Product Development) em suas atividades (CHILDERHOUSE; AITKEN; TOWILL, 2002; VONDEREMBSE et al., 2006). Muitos métodos de gestão da cadeia pressupõem que decisões sobre novos produtos já tenham sido tomadas, abrindo-se mão de gerenciá-las junto às demais atividades da SCM (SIMCHI-LEVI; KAMINSKY; SIMCHI-LEVI, 2002). A constatação de que tal contexto pouco se verifica na prática, resultou em estudos focados na necessidade de mais coordenação entre atividades de SCM e NPD (HULT; SWAN, 2003; RUNGTUSANATHAM; FORZA, 2005).

Recentemente, o mercado de moda rápida foi definido como estratégico por fabricantes nacionais, dentre estes os calçadistas, por ser uma alternativa capaz de enfrentar a concorrência dos países asiáticos com menores custos de mão de obra. A concorrência no setor calçadista é caracterizada por um número elevado de empresas em competição, existência de rivalidade, diferença considerável entre oferta e procura, competição externa, alta dependência de mão de obra e seus produtos devem acompanhar tendências de moda internacional, o que pode dificultar a organização interna e o planejamento e controle da produção (SILVA; FERNANDES, 2008). Há alta variedade de produtos feitos sob encomenda, cujo fator crítico de sucesso é o tempo de resposta, sem perda de produtividade e qualidade. (FERNANDES et al., 2012).

Os fabricantes de calçados nacionais, e em particular, os fabricantes da região de Nova Serrana, em Minas Gerais, têm se interessado em aumentar sua competitividade no mercado de moda rápida. Depois de debate no SINDINOVA (Sindicato da Indústria do Calçado de Nova Serrana, que congrega atualmente 367 empresas), cerca de 750 profissionais, representantes de pequenos, médios e grandes fabricantes, concluíram que a exploração do mercado de moda rápida exige mais diversidade de materiais, em baixos volumes e a custos menores. Nesse contexto, fabricantes de calçados, fornecedores de insumos, a ASSINTECAL (Associação Brasileira de Empresas de Componentes para Couro, Calçados e Artefatos) e um grupo de pesquisadores acadêmicos financiados pelo CNPq articularam um projeto de pesquisa em âmbito nacional denominado Materioteca. Apesar do interesse inicial de compradores e fornecedores, a Materioteca não atingiu seus objetivos. Depois de dois anos, cerca de apenas sessenta empresas, em um universo de trezentos e vinte possíveis, expunham pequena variedade de materiais. Em fórum realizado em 2009, os pesquisadores foram chamados para analisar os problemas observados.

$\mathrm{O}$ objetivo deste artigo foi investigar porque a Materioteca não atingiu seus objetivos. O método de pesquisa foi o estudo de caso exploratório múltiplo. A investigação requereu a aplicação de métodos qualitativos de pesquisa de formas a explicitar os constructos relevantes e o estabelecimento de proposições sobre suas interações (EISENHARDT, 1989). A determinação teórica dos constructos foi baseada em Glaser e Strauss (1967). O artigo revisa incertezas em demandas (característica maior do setor de moda rápida), flexibilidade de suprimento e desenvolvimento de produto em cadeias de suprimento. Seguem metodologia da pesquisa, resultados, análise e conclusões.

Até quanto foi pesquisado, não foram encontrados estudos de caso similares ao ora apresentado, tratando de intervenções setoriais em arranjos produtivos calçadistas. A pesquisa foi inteiramente financiada pelo CNPq.

\section{Revisão}

\subsection{Incertezas no ambiente de negócios}

Flutuações na demanda, problemas de suprimento, modificações em sistemas produtivos e mudanças tecnológicas produzem incertezas e exigem ações estratégicas no nível de coordenação da cadeia de suprimentos (PAULRAJ; CHEN, 2007). Lee (2002) propôs um modelo para formulação da estratégia de suprimentos em cenário de incerteza com base nos elementos suprimento e demanda. Para o autor, a incerteza de demanda advém da baixa acuracidade na informação mercadológica de um produto. Segundo Fisher (1997), esta incerteza é menor em produtos funcionais do que em produtos inovadores.

Autores têm tratado a gestão de incertezas como parte da gestão de risco em cadeias (TUNCEL; ALPAN, 2010; THUN; HOENIG, 2011; TANG; MUSA, 2011). Ao se verem expostas a riscos, em parte oriundos de incertezas e da pouca acuracidade na informação, as cadeias de suprimentos podem optar por reorganizar suas práticas de gestão (WAGNER; BODE, 2008). Tal reorganização foi foco de estudos, tais como os de Childerhouse e Towill (2004), Bhatnagar e Sohal (2005), Sawhney (2006), Avittathur e Swamidass (2007), Stevenson e Spring (2007) e Sodhi, Son e Tang (2012). Tais estudos adotam duas linhas: entendimento das fontes de incerteza; e técnicas para lidar com ela. As soluções mais observadas têm sido de dois tipos: reduzir o impacto 
negativo de eventos inesperados que já aconteceram; e reduzir a probabilidade de ocorrência de tais eventos (BUDDRESS, 2013).

A primeira linha objetiva mitigar, ou mesmo eliminar, os indutores da incerteza (VAN DER VORST; BEULENS, 2002; CHILDERHOUSE; TOWILL, 2004). Ho, Chi e Tai (2005) analisaram a adoção de ferramentas de e-commerce para aumentar a coordenação entre parceiros de cadeia e monitorar o desempenho da cadeia como um todo. Mo (2002) propôs uma estratégia de subordinação híbrida que permite estoques de produtos semiacabados ou acabados. Buddress (2013) fala em fontes alternativas para um mesmo suprimento, suprimentos alternativos para um mesmo uso; e estoques de segurança mais elevados e mais distribuídos. Os estudos descritos julgam viável aplicar mecanismos de coordenação ou tecnologia da informação para reduzir ou mesmo eliminar as fontes das incertezas. Uma alternativa é o mapeamento de fontes de riscos ao longo da cadeia, atribuindo-lhes probabilidades, o que permite o uso de métodos numéricos de gestão, como em Lockamy e McCormack (2010), ou reconfiguração de facilidades, como em Qi, Shen e Snyder (2010).

A segunda linha focalizou a adoção de estratégias de flexibilidade. Segundo Chan e Chan (2010), cadeias de suprimento devem ser mais flexíveis e adaptativas se suas operações foram sujeitas a incertezas, principalmente relacionadas a demandas de clientes e capacidades de fornecedores. Autores investigaram a relação entre flexibilidade e incerteza ambiental e entre flexibilidade e desempenho (BHATNAGAR; SOHAL, 2005; EBBEN; JOHNSON, 2005; SÁNCHEZ; PÉREZ, 2005; KETOKIVI, 2006; SAWHNEY, 2006). Vickery, Calantone e Dröge (1999) postulam que a flexibilidade de volume e a flexibilidade de lançamento são alternativas para incertezas. Avittathur e Swamidass (2007) investigaram como um relacionamento flexível entre uma empresa focal e seus fornecedores afeta a lucratividade empresarial. Os achados indicam que os indicadores de lucratividade são maiores quando as estratégias de flexibilidade da empresa focal e de seus fornecedores encontram-se alinhadas.

\subsection{Flexibilidade nas cadeias de suprimento: relação entre produto e suprimento}

A mitigação dos efeitos das incertezas em ambientes de negócios requer a estruturação de cadeias de suprimento flexíveis (CHRISTOPHER; HOLWEG, 2011). Uma definição clássica de flexibilidade foi dada por Gerwin (1993): é a capacidade de um sistema produtivo responder adaptativamente a incertezas ambientais. Flexibilidade de cadeia de suprimentos aparece desde os anos 1990, nos estudos de Lau (1996), Fawcett, Calantone e Smith (1996), Narasimhan e Das (1999, 2000), Koste (1999), Das
(2001) e Olhager e West (2002). A flexibilidade de cadeia de suprimentos pode ser definida como a elasticidade observada no relacionamento compradorvendedor sob condições incertas de suprimento (DAS; ABDEL-MALEK, 2003). A noção de flexibilidade de cadeia foi ampliada por Duclos, Vokurka e Lummus (2003), que propuseram um modelo conceitual de seis elementos, posteriormente reduzidos para cinco por Lummus, Duclos e Vokurka (2003). Os cinco elementos são: sistema operacional, processos logísticos, rede de suprimento, design organizacional e flexibilidade dos sistemas de informações. As noções de serviços não associados à manufatura e de complexidade presente na cadeia (SELLITTO et al., 2010) expandiram o entendimento acerca da necessidade de gerenciar a flexibilidade em cadeias de suprimentos. Baseados em referências, Stevenson e Spring (2007) sintetizaram o nível de flexibilidade da cadeia às seguintes dimensões: (i) robustez, envolvendo a variedade de eventos aos quais a cadeia é capaz de reagir satisfatoriamente na configuração atual; (ii) flexibilidade de reconfiguração, envolvendo a facilidade com que a cadeia pode se adaptar por meio de autorreorganização; (iii) flexibilidade de relacionamentos, envolvendo a capacidade de estabelecer novos relacionamentos a montante e a jusante como resposta a variações de mercado; (iv) flexibilidade logística, envolvendo a capacidade de alterar fontes de suprimento a custos razoáveis; (v) flexibilidade de aprendizado, envolvendo a capacidade de adquirir e alinhar conhecimentos e habilidades em função das demandas de mercado; e (vi) flexibilidade informacional, envolvendo a capacidade de alinhar sistemas de informação. Por fim, Gosling, Purvis e Naim (2010) observaram que a flexibilidade na cadeia advém de dois antecedentes: flexibilidade no suprimento, relacionada à capacidade coletiva de reconfigurar uma rede de fornecimentos mediante risco; e flexibilidade dos fornecedores, relacionada à capacidade de adaptação individual das empresas que atuam como fornecedores. Na mesma linha, Pires e Sacomano Neto (2010) estudaram o papel de sistemistas da cadeia automotiva como geradores de flexibilidade.

A coordenação entre a gestão da cadeia de suprimentos e o desenvolvimento de novos produtos (NPD) é uma alternativa para aumentar a flexibilidade das cadeias. A SCM deve incluir o NPD como atividade de gestão ao longo da cadeia de valor (CHILDERHOUSE; AITKEN; TOWILL, 2002; VONDEREMBSE et al., 2006). Todavia, nem sempre o desenvolvimento de produtos está contemplado nos objetivos imediatos da SCM (SIMCHI-LEVI; KAMINSKY; SIMCHI-LEVI, 2002; HULT; SWAN, 2003; RUNGTUSANATHAM; FORZA, 2005). Abordando a integração entre SCM e NPD, Pero et al. (2010) postulam que as abordagens observadas na 
literatura podem ser orientadas ao NPD ou à SCM. O Quadro 1 sintetiza as abordagens, segundo os autores.

A análise do conteúdo das referências listadas revela que as abordagens orientadas ao NPD buscam antecipar as restrições nos primeiros estágios do desenvolvimento do produto. Portanto, é denominada de "design para a cadeia de suprimentos" (LEE; SASSER, 1995). Os modelos de suporte à decisão orientados ao NPD envolvem listagens de materiais (BOM - bill-ofmaterials) e arquiteturas de produto. Em tais modelos, inicialmente os custos são expressos como uma função da estrutura de produto (por exemplo, transporte e estoques na cadeia de suprimentos). Posteriormente, é buscada uma otimização da função custo, de forma a obter a melhor estrutura de produto para uma dada cadeia de suprimentos (BLACKHURTS; WU; O'GRADY, 2005; HUANG; ZHANG; LIANG, 2005; LEE; SASSER, 1995). Conforme Ulrich (1995), arquitetura de produtos é o esquema pelo qual as funções do produto são alocadas aos seus componentes físicos. Krishnan e Ulrich (2001) postulam que os trade-offs entre produto, processo e estrutura da cadeia de suprimentos se ajustam melhor à abordagem da arquitetura de produtos do que à da BOM. Alguns modelos analisam o relacionamento entre as características da arquitetura de produtos e as decisões da cadeia de suprimentos (FIXSON, 2005). Outros abordam a seleção das estratégias de suprimento (NOVAK; EPPINGER, 2001) ou, então, focam a postergação das decisões de configuração de produto e a consequente alocação do ponto de diferenciação de produto na cadeia de suprimentos (FEITZINGER; LEE, 1997).

Outra linha de abordagem é orientada à SCM e considera que o produto e suas características estão definidos. A literatura apresenta dois modelos nessa linha. O primeiro define a estratégia da cadeia de suprimentos (Enxuta, Ágil ou Híbrida) dependendo das variáveis de produto e de mercado, por exemplo: variabilidade, variedade e volumes (VONDEREMBSE et al., 2006; CHRISTOPHER; LOWSON; PECK, 2004; HUANG; UPPAL; SHI, 2002; FISHER, 1997). O segundo investiga como a estrutura da cadeia de suprimentos é impactada pela estrutura de produto. Usualmente, esses modelos consideram o nível de modularidade e variedade do produto (SALVADOR; FORZA; RUNGTUSANATHAM, 2002). Outros estudos examinam os efeitos da modularidade de produto (intrafirma e interfirmas) em relacionamentos estabelecidos para o design de produto (SANCHEZ; MAHONEY, 1996) e estrutura organizacional (SCHILLING; STEENSMA, 2001). A premissa básica desses estudos é a de que produtos modulares levam a organizações modulares. Conforme a literatura, uma organização é denominada modular quando consiste de uma rede de organizações minimamente controladas e flexíveis a recombinações em seus arranjos. A modularidade implica que os times de design de produto trabalhem autonomamente em módulos físicos independentes. O conceito de modularidade também pode ser estendido às cadeias de suprimento (PERO et al., 2010).

A modularidade de produto também está relacionada à variedade desejada de produtos. Decisões de variedade são tomadas durante o NPD e impactam diretamente no desempenho operacional da cadeia de suprimentos. O relacionamento entre variedade e a cadeia de suprimentos foi estudado com base nos custos diretos e indiretos da produção, prazos de entrega, níveis de estoque, impacto na política de compras e planos de produção (HOLMSTRÖM et al., 2006), assim como nos custos comportamentais advindos da variedade de produtos (BRUN; CAPRA; MIRAGLIOTTA, 2006). A literatura considera variedade e modularidade como principais entregas de um desenvolvimento de produto com capacidade

Quadro 1. Principais abordagens e variáveis descritas na literatura.

\begin{tabular}{|c|c|c|c|}
\hline $\begin{array}{l}\text { Abordagem de } \\
\text { coordenação }\end{array}$ & $\begin{array}{c}\text { Variáveis afetas à } \\
\text { cadeia }\end{array}$ & $\begin{array}{c}\text { Variáveis afetas } \\
\text { ao produto }\end{array}$ & Referências \\
\hline \multirow[b]{2}{*}{$\begin{array}{c}\text { Pró-ativa e orientada } \\
\text { ao projeto (NPD) }\end{array}$} & Estrutura da cadeia & Arquitetura & \multirow{2}{*}{$\begin{array}{l}\text { Lee e Sasser (1995), Huang, Zhang e Liang } \\
\text { (2005), Qi, Shen e Snyder (2010), Blackhurts, } \\
\text { Wu e O'Grady (2005), Novak e Eppinger } \\
\text { (2001) e Feitzinger e Lee (1997) }\end{array}$} \\
\hline & Custos da cadeia & $\mathrm{BOM}$ & \\
\hline \multirow{4}{*}{$\begin{array}{l}\text { Reativa e orientada } \\
\text { à gestão da cadeia } \\
(\text { SCM) }\end{array}$} & Estratégia da cadeia & $\begin{array}{l}\text { Inovação de } \\
\text { produto }\end{array}$ & $\begin{array}{l}\text { Sodhi, Son e Tang (2012), Childerhouse, } \\
\text { Aitken e Towill (2002), Vonderembse et al. } \\
\text { (2006) e Fisher (1997) }\end{array}$ \\
\hline & Estrutura da cadeia & Modularidade & \multirow{3}{*}{$\begin{array}{l}\text { Salvador, Forza e Rungtusanatham (2002), } \\
\text { Fine (1998), Sturgeon (2002), Doran et al. } \\
\text { (2007), Ro, Liker e Fixon (2007), Lau e Yam } \\
\text { (2005), Fisher e Ittner (1999), MacDuffie, } \\
\text { Sethuraman e Fisher (1996), Miller e } \\
\text { Vollmann (1985), Brun, Capra e Miragliotta } \\
\text { (2006) e Gosling, Purvis e Naim (2010) }\end{array}$} \\
\hline & Custos & Variedade & \\
\hline & $\begin{array}{c}\text { Relação comprador- } \\
\text { vendedor }\end{array}$ & $X$ & \\
\hline
\end{tabular}


de geração de impacto na cadeia de suprimentos. Relativamente à cadeia de suprimentos, as variáveis que têm sido estudadas se relacionam a aspectos estratégicos, em particular a estrutura da rede de fornecedores e a intensidade de colaboração entre os parceiros da cadeia (PERO et al., 2010).

\section{A pesquisa}

A Materioteca foi reconhecida pela associação de classe Assintecal (Associação Brasileira de Empresas de Componentes para Couro, Calçados e Artefatos) como uma intervenção setorial. Seu objetivo era ser uma exposição permanente, localizada na região de Nova Serrana, dos materiais produzidos pela maioria dos cerca de 320 fabricantes de insumos localizados em diversas partes do País (especialmente aqueles insumos que conferem aparência ao produto final, como adereços, solados, tecidos, couro) para os compradores da indústria calçadista da região de Nova Serrana.

A Figura 1 apresenta um esquema conceitual de funcionamento.

A Materioteca foi concebida como uma exposição nacional para os compradores da região de Nova Serrana. No entanto, após o interesse inicial demonstrado por expressivo número de empresas, a Materioteca não atingiu seus objetivos. Esperava-se que se tornasse a principal fonte de abastecimento de insumos dos fabricantes calçadistas da região. Também se esperava expressiva redução de custo de venda de fornecedores e aumento na variedade e na inovação presente nos insumos. Por fim, também era objetivo reduzir prazos de entrega de fornecimentos e aumentar a flexibilidade dos produtos finais dos fabricantes calçadistas da região de Nova Serrana. Eventuais avanços conceituais poderiam ser transmitidos a outras regiões produtoras de calçados e de fast fashion do Brasil.

A Assintecal decidiu iniciar uma pesquisa para descobrir as causas deste não atingimento para aumentar a probabilidade de sucesso de eventuais novas tentativas. Então, a questão de pesquisa foi: Por que a Materioteca não produziu os resultados desejados? A questão de pesquisa é do tipo por que. Segundo Yin (2009), tais questões podem ser respondidas por estudos de caso. Foram estudados quinze fabricantes de calçados da região de Nova Serrana e quinze fornecedores de insumos de pequeno, médio e grande porte, de várias partes do Brasil. $\mathrm{O}$ objetivo principal foi descobrir porque a Materioteca falhou. Os objetivos específicos foram: (i) construir uma estrutura de variáveis que pudesse descrever o conceito de flexibilidade e relacioná-lo com o atendimento de demandas de clientes; (ii) investigar a situação destas variáveis no arranjo produtivo de Nova Serrana; e (iii) concluir acerca de que variáveis afetaram o desempenho da intervenção setorial.

A investigação adotou a postura ambivalente proposta por Stevenson e Spring (2009), que mescla análise teórica reflexiva, que aponta variáveis de pesquisa; e investigação empírica do estado destas variáveis. Em estudos qualitativos, deve-se verificar as validades de construto, interna e externa da pesquisa. A validade de constructo garante que o que se está medindo realmente mede o objeto de pesquisa. A validade interna verifica até que ponto as observações e descrições representam a realidade. A validade

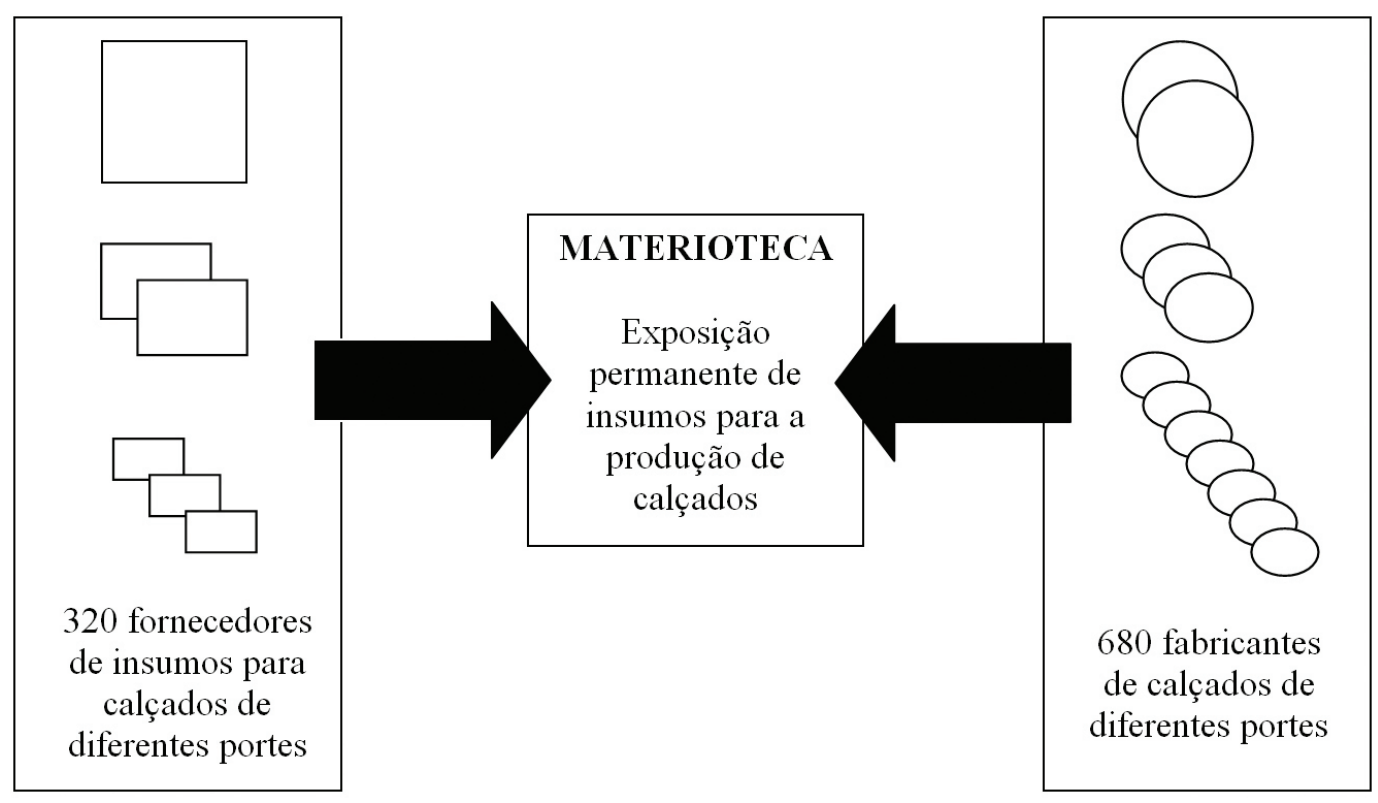

Figura 1. Esquema conceitual da Materioteca. 
externa verifica até que ponto as descrições obtidas do objeto de pesquisa são comparáveis entre diferentes contextos em que o objeto se encontre (GOETZ; LECOMPTE, 1984; GOODWIN; GOODWIN, 1984). A validade de constructo é garantida pela revisão teórica, principalmente pelas referências citadas no Quadro 2. A validade interna é assegurada por terem os pesquisadores entrevistado diretamente os agentes envolvidos nas decisões e visualizado de fato os cenários estudados, sem recorrer a intermediários ou a registros documentais passados. Adicionalmente, dois pesquisadores participaram de cada entrevista, comparando posteriormente os achados. A validade externa é menos importante, pois ainda não é objetivo de pesquisa a generalização de achados.

O método de pesquisa foi o estudo de caso múltiplo exploratório. A escolha é reforçada pelo pouco referencial encontrado, até quanto se pesquisou, acerca das variáveis e dos fenômenos envolvidos nesta relação (BENBASAT; GOLDSTEIN; MEAD, 1987; MEREDITH, 1998). Estudos de caso são apropriados para aumentar o entendimento de um fenômeno complexo que ainda não foi suficientemente desenvolvido na literatura (BAKER, 2001; STRAUSS; CORBIN, 1998; SCHOLZ; TIETJE, 2002). Estudos de caso consideram o fenômeno em seu contexto, sem necessidade de isolá-lo do ambiente, permitindo uma percepção sistêmica do objeto (YIN, 2009). Estudos de caso múltiplos são indicados na exploração de novas teorias por aumentarem a validade externa, evitarem o viés do observador (HANDFIELD; MELNYK, 1998; MEREDITH, 1998; VOSS; TSIKRIKTSIS; FROHLICH, 2002), permitirem triangulação de informações e aumentarem a eventual generalidade de achados de pesquisa (VOSS; TSIKRIKTSIS; FROHLICH, 2002; YIN, 2009). Estudos de caso exploratórios podem contribuir com novos e diversos elementos para a construção de teorias
(EISENHARDT, 1989; EISENHARDT; GRAEBNER, 2007). Estudos de caso permitem gerar conhecimento mais aprofundado acerca de um objeto isolado do que permitiria um survey (NORDIN, 2005), desde que um suficiente número de casos tenha sido observado. Sempre que possível, para confiabilidade, informações devem ser trianguladas (EISENHARDT, 1989; JICK, 1979, EISENHARDT; GRAEBNER, 2007). Casos podem ter mais alto impacto, pois podem produzir novas percepções sobre fenômenos complexos observados no campo da gerência de operações (VOSS; TSIKRIKTSIS; FROHLICH, 2002). Estudos de caso podem ser úteis no desenvolvimento de teorias por prover visões aprofundadas de fenômenos empíricos e suas relações com os contextos (DUBOIS; GADDE, 2010). Muitos conceitos e teorias atuais em gerência de operações foram desenvolvidos a partir de estudos de caso (BOULAKSIL; FRANSOO, 2010). Estudos de caso também podem ser úteis na proposição de hipóteses que formalizem regularidades observadas em unidades de análise (DUBOIS; GADDE, 2010). Tal procedimento, ou seja, o uso de estudos de caso para a proposição de hipóteses, foi adotado nesta pesquisa.

O método de trabalho foi: (i) grupos focados com empresários para coleta de informações acerca da Materioteca, cuja entrega foi a estrutura de variáveis a investigar; (ii) reunião dos pesquisadores com gestores da ASSINTECAL e dirigentes do SINDINOVA, cuja entrega foi uma seleção de empresas fabricantes de calçados e fornecedores de insumos para serem as unidades de análise da pesquisa; (iii) revisão dos achados pelos pesquisadores, cuja entrega foi um protocolo de pesquisa (variáveis de controle); (iv) visita aos fabricantes e fornecedores selecionados para aplicação do protocolo e observação não participante, cuja entrega foi um conjunto de dados qualitativos; e (v) análise e reflexão dos pesquisadores, cuja entrega

Quadro 2. Constructos e variáveis da pesquisa.

\begin{tabular}{|c|c|c|c|}
\hline Constructo & Referências & Variável & Descrição \\
\hline \multirow{4}{*}{ Insumos } & \multirow{4}{*}{$\begin{array}{l}\text { Vickery, Calantone e Dröge (1999), Pujawan } \\
\text { (2004), Kumar, Fantazy e Kumar (2006), } \\
\text { Zhang, Vonderembse e Lim (2006), Fantazy, } \\
\text { Kumar e Kumar (2009), Gosling, Purvis e } \\
\text { Naim (2010) e Pero et al. (2010) }\end{array}$} & Variedade & $\begin{array}{l}\text { Diversidade de opções de um } \\
\text { mesmo insumo }\end{array}$ \\
\hline & & Inovação & $\begin{array}{l}\text { Atualidade do design dos } \\
\text { materiais expostos }\end{array}$ \\
\hline & & Modularidade & $\begin{array}{l}\text { Modularidade dos insumos } \\
\text { expostos na Materioteca }\end{array}$ \\
\hline & & Oferta & $\begin{array}{l}\text { Adequação dos insumos expostos } \\
\text { às demandas locais }\end{array}$ \\
\hline \multirow{3}{*}{ Suprimento } & \multirow{3}{*}{$\begin{array}{l}\text { Vickery, Calantone e Dröge (1999), Duclos, } \\
\text { Vokurka e Lummus (2003), Pujawan (2004), } \\
\text { Sanchez e Perez (2005), Lumas (2005), Zhang, } \\
\text { Vonderembse e Lim (2006), Kumar, Fantazy } \\
\text { e Kumar (2006), Fantazy, Kumar e Kumar } \\
\text { (2009), Gosling, Purvis e Naim (2010) e } \\
\text { Pero et al. (2010) }\end{array}$} & Entregas & $\begin{array}{l}\text { Pontualidade e agilidade nas } \\
\text { entregas dos itens adquiridos na } \\
\text { Materioteca }\end{array}$ \\
\hline & & Condiçõos & $\begin{array}{l}\text { Preços e condições de pagamento } \\
\text { oferecidas aos compradores }\end{array}$ \\
\hline & & Alternativas & $\begin{array}{l}\text { Diversidade de expositores de um } \\
\text { mesmo item }\end{array}$ \\
\hline
\end{tabular}


foi a organização e comparação das informações, dedução de achados e análise geral dos resultados.

O objetivo da Materioteca era ser uma exposição permanente de materiais e insumos que pudessem ser úteis para os fabricantes de calçados da região de Nova Serrana. Qualquer fornecedor nacional poderia expor suas linhas de produtos, mas a preferência de compra era para os fabricantes da região de Nova Serrana, para que se garantisse a vantagem de localização: um comprador poderia, em uma única visita, examinar várias ofertas de insumos. Por conveniência e facilidade de acesso, e dado que o interesse de pesquisa era localizado, escolheu-se pesquisar a cadeia de suprimentos desta região. Similar critério foi utilizado por Barratt, Choi e Li (2011). A escolha de fornecedores de componentes e dos fabricantes de calçados objetivou conferir abrangência à pesquisa e validade às conclusões, conforme Voss, Tsikriktsis e Frohlich (2002). Os fabricantes se encaixam no perfil definido por Abecassis-Moedas (2006) para a indústria da moda: Empresas de Manufatura Tradicionais (EMT), que fazem design e produzem para redes de varejo ou proprietárias de grifes que subcontratam a produção.

\subsection{Protocolo de pesquisa}

Com base na teoria revisada, foi estruturado o protocolo de pesquisa. Sua elaboração considerou os constructos e variáveis do Quadro 2.
O mesmo protocolo foi utilizado com fornecedores e fabricantes, como sugerido por Eisenhardt (1989). As questões foram semiestruturadas e foram refinadas à medida que avançavam as entrevistas. Similar refinamento foi usado por Oliva e Watson (2011) e se constitui em procedimento observado no desenvolvimento de teorias fundamentadas (GLASER; STRAUSS, 1967). Em cada entrevista, objetivou-se avaliar a percepção acerca da intervenção realizada, suas contribuições, limitações e mudanças requeridas. Nas sessões de grupo focado, foi descartada a variável modularidade em função das peculiaridades do mercado fast fashion.

\subsection{Seleção das unidades de análise}

O Quadro 3 apresenta o perfil dos fabricantes de calçados investigados. Estes foram divididos em três grupos, conforme critérios do SINDINOVA. As grandes empresas representam cerca de $3 \%$ do total de fabricantes de calçados da região e mais de $65 \%$ do potencial local de negócios. As empresas médias representam cerca de $33 \%$ do total de empresas da região. As pequenas representam cerca de $62 \%$.

O Quadro 4 apresenta o perfil dos fabricantes de insumos conforme critérios da ASSINTECAL.

Todas as empresas entrevistadas participaram da concepção e implantação da Materioteca de Nova Serrana. No total, foram realizadas trinta entrevistas com diretores das empresas selecionadas (duração

Quadro 3. Perfil dos fabricantes de calçados.

\begin{tabular}{|c|c|c|c|c|}
\hline Porte & Pares/dia & Localização & Empresa & Mercados \\
\hline \multirow{2}{*}{ Grande } & \multirow{2}{*}{ Acima de 3.000} & \multirow{2}{*}{ Nova Serrana } & $\mathrm{C} 1, \mathrm{C} 2$ e $\mathrm{C} 3$ & Grandes redes de lojas \\
\hline & & & $\mathrm{C} 4$ e $\mathrm{C} 5$ & Grandes e médias redes de lojas \\
\hline \multirow{2}{*}{ Médio } & \multirow{2}{*}{ Entre 500 e 3.000} & \multirow{2}{*}{ Nova Serrana } & C6 e C7 & Grandes redes de lojas \\
\hline & & & $\mathrm{C} 8, \mathrm{C} 9$ e $\mathrm{C} 10$ & Grandes e médias redes de lojas \\
\hline \multirow{3}{*}{ Pequeno } & \multirow{3}{*}{ Abaixo de 500} & \multirow{3}{*}{ Nova Serrana } & $\mathrm{C} 11$ & Grandes redes de lojas \\
\hline & & & $\mathrm{C} 12$ e $\mathrm{C} 13$ & Grandes e médias redes de lojas \\
\hline & & & $\mathrm{C} 14$ e C15 & Pequenas redes de lojas e boutiques \\
\hline
\end{tabular}

Quadro 4. Perfil dos fabricantes de insumos.

\begin{tabular}{|c|c|c|l|l|}
\hline Porte & Insumo & Empresa & \multicolumn{1}{|c|}{ Localização } & \multicolumn{1}{c|}{ Principais clientes } \\
\hline \multirow{4}{*}{ Grande } & Sintéticos & I1 & São Paulo & Grandes e médios fabricantes de calçados \\
\cline { 2 - 5 } & Adornos & I2 e I3 & Rio Grande do Sul & Grandes e médios fabricantes de calçados \\
\cline { 2 - 5 } & \multirow{2}{*}{ Solados } & I4 & São Paulo & Grandes e médios fabricantes de calçados \\
\cline { 2 - 5 } & I5 & Rio Grande do Sul & Grandes, médios e pequenos fabricantes de calçados \\
\hline \multirow{3}{*}{ Médio } & Sintéticos & I6 e I7 & Rio Grande do Sul & Grandes e médios fabricantes de calçados \\
\cline { 2 - 5 } & Adornos & I8 e I9 & São Paulo & Grandes, médios e pequenos fabricantes de calçados \\
\cline { 2 - 5 } & Solados & I10 & Minas Gerais & Grandes, médios e pequenos fabricantes de calçados \\
\hline \multirow{3}{*}{ Pequeno } & Adornos & I11, I12 e I13 & Rio Grande do Sul & Grandes, médios e pequenos fabricantes de calçados \\
\cline { 2 - 5 } & Tecidos & I14 e I15 & $\begin{array}{l}\text { Rio Grande do Sul } \\
\text { e São Paulo }\end{array}$ & Médios e pequenos fabricantes de calçados \\
\hline
\end{tabular}


média de quarenta e cinco minutos). Cada entrevista foi conduzida por dois pesquisadores. Os achados foram registrados por meio eletrônico para posterior reaproveitamento.

As atividades e a organização da indústria e do trabalho na região de Nova Serrana já foram amplamente estudadas na literatura. Dentre outros, pode-se destacar os estudos de Vasconcelos e Oliveira (2012), Crocco et al. (2010), Suzigam et al. (2005) e Enoque e Pimenta (2010). Santos e Romeiro Filho (2013) publicaram dados sobre a atividade calçadista da região de Nova Serrana. Segundo o que foi publicado pelos autores, em 2010 havia 687 empresas ativas na indústria (em 2013, o sindicato patronal representava 367 empresas associadas), incluindo as empresas de terceirização e prestação de serviços. Portanto, a amostra de compradores (15) corresponde a cerca de $2 \%$ da população total de empresas e a cerca de $4 \%$ da população de empresas sindicalizadas. Na outra mão, a amostra de vendedores (15) corresponde a cerca de 5\% da população total (cerca de 320) de fabricantes de insumos associados à ASSINTECAL.

\subsection{Análise dos dados}

Inicialmente, cada pesquisador sumarizou os achados das suas entrevistas. Posteriormente, os sumários foram confrontados com o outro participante da mesma entrevista, de forma a evitar viés advindo de opinião pessoal. Um relatório descrevendo o consenso entre os pesquisadores em cada questão era então gerado e, posteriormente, apresentado aos entrevistados para validação.

As sínteses aprovadas pelos entrevistados foram codificadas por constructo, variável de investigação e perfil de empresa respondente (fabricante ou fornecedor e tamanho da empresa). Essa codificação objetivou desvelar padrões dentro de cada perfil de empresas investigado (análise longitudinal dos casos ou case analysis). Os resultados dessa etapa são apresentados nos Apêndices I, II, III e IV. Codificações e análises adicionais orientadas pelos constructos investigados permitiram a confrontação entre fabricantes de calçados e fornecedores (análise transversal ou cross-case analysis). Da análise da conjunção desses constructos provém uma explanação dos motivos pelos quais a Materioteca de Nova Serrana não gerou os resultados esperados.

\section{Achados, análise, proposições}

Por clareza e objetividade, procurou-se reduzir a apresentação do conteúdo de entrevistas e observações não participantes, porém sem perder a generalidade e a tipicidade dentro do universo de pesquisa. São apresentados os achados e as análises longitudinais de cada perfil e a análise transversal dos casos. Ao fim, sintetizaram-se os achados e lançaram-se proposições para futuras pesquisas.

\subsection{Análise longitudinal: Fabricantes}

O Apêndice I apresenta o resultado da codificação dos achados afetos ao constructo Insumos identificados junto aos fabricantes calçadistas. Observa-se que os grandes fabricantes reclamam da pequena variedade, do baixo índice de inovação e da falta de foco da Materioteca. Os pequenos e médios fabricantes têm a mesma visão, contudo demonstraram ser mais afetados pela pouca variedade e inovação, pois não são visitados por representantes dos fornecedores na mesma frequência dos grandes.

O Apêndice II apresenta a codificação do constructo Suprimentos junto aos fabricantes calçadistas. Observa-se que os grandes fabricantes não explicitaram problemas de entregas e condições de fornecimento, ao passo que os pequenos e médios o fizeram. Mesmo assim estes ressaltaram que a Materioteca é uma alternativa para o aumento de sua flexibilidade em produtos de nicho. Houve unanimidade entre as empresas quanto ao baixo número de expositores. Todos os fabricantes calçadistas declararam que a oferta de insumos para o mercado casual, ao contrário do esportivo, parece ter reduzido as possibilidades de negócios na Materioteca. O Quadro 5 sintetiza os achados colhidos junto aos fabricantes de calçados.

\subsection{Análise longitudinal: Fornecedores}

O Apêndice III apresenta a codificação dos achados do constructo Insumos junto aos fornecedores. Observa-se que os insumos expostos pelos fornecedores na Materioteca são os que

Quadro 5. Síntese dos achados: fabricantes.

\begin{tabular}{|c|c|l|}
\hline Constructo & Variável & \multicolumn{1}{c|}{ Síntese } \\
\hline \multirow{4}{*}{ Insumos } & Variedade & Unanimidade no tocante a pouca variedade \\
\cline { 2 - 3 } & Inovação & Baixo grau de inovação na oferta \\
\cline { 2 - 3 } & Oferta & Foco no mercado casual, em vez do esportivo \\
\hline \multirow{3}{*}{ Suprimento } & Entregas & Problemática para pequenos e médios fabricantes de calçados \\
\cline { 2 - 3 } & Alternativas & Baixo número de expositores \\
\cline { 2 - 3 } & Condições & Problemática para pequenos e médios fabricantes de calçados \\
\hline
\end{tabular}


não estão sujeitos à condição de exclusividade, independentemente do porte do expositor. Tal condição reduz a variedade passível de ser exposta e é arbitrada pelos grandes fabricantes. Cumpre destacar que essa restrição se constitui em alternativa para a ampliação do lucro passível de ser auferido pelos grandes calçadistas e seus fornecedores. A exposição de materiais inovadores é afetada pela condição de exclusividade e pela possibilidade de cópia por concorrentes. A possibilidade de conflito com os canais estabelecidos limita o aumento da oferta de insumos para calçados esportivos (maior parte da demanda da região) por parte das grandes e médias fornecedoras, reduzindo a atratividade da Materioteca para a maioria dos fabricantes de calçados. Os pequenos fornecedores declararam que não possuem estrutura para gerenciar a variedade a ser exposta na Materioteca. Com efeito, sua participação na Materioteca objetiva testar um novo canal de vendas de baixo custo para o mercado casual da região.

O Apêndice IV apresenta a codificação dos achados afetos ao constructo Suprimentos junto aos fornecedores de insumos. Quanto à variável Entregas, apurou-se que todos os fornecedores atendem aos pedidos da Materioteca em janelas ociosas de sua capacidade produtiva, haja vista a baixa margem de lucro dos produtos sem exclusividade, em comparação aos exclusivos. Os pequenos fornecedores declararam não possuir uma estrutura adequada para o atendimento de pedidos não exclusivos. Na variável Alternativas, verificou-se que grandes e médios fornecedores relutam em participar da Materioteca em função da possibilidade de conflitos com os canais estabelecidos. A falta de estrutura para mapear oportunidades de mercado também é apontada pelos pequenos fornecedores como uma barreira à sua inserção na Materioteca. $\mathrm{Na}$ variável Condições, os achados indicam que todos os fornecedores entendem que o baixo volume de venda na Materioteca resulta em aumento no preço dos insumos. O Quadro 6 sintetiza os achados junto aos fornecedores de insumos.

\subsection{Análise transversal: Insumos}

As análises dos achados das variáveis Variedade e Inovação revelaram que os fornecedores de insumos estão sujeitos à condição de exclusividade imposta pelos grandes fabricantes calçadistas. Esta exigência limita a variedade de itens expostos na Materioteca e prejudica os pequenos e médios fabricantes de calçados, haja vista que estes, devido ao pequeno potencial de compra, não são visitados regularmente pelos representantes dos fornecedores de insumos.

Quanto à inovação, devido ao risco de cópia, observou-se que os fornecedores de insumos não possuem grande interesse em expor itens inovadores na Materioteca. Novamente aqui se identifica o prejuízo dos pequenos e médios fabricantes calçadistas, os quais veem na Materioteca uma alternativa complementar para seus produtos de nicho. Com efeito, a demanda por exclusividade feita pelos grandes fabricantes objetiva, em última instância, restringir a variedade e a inovação dos pequenos e médios fabricantes de calçados. Essa restrição confere aos grandes fabricantes uma importante vantagem competitiva perante seus concorrentes de menor porte.

Nesse contexto, é possível supor que a pequena variedade e o baixo grau de inovação identificados no estudo decorrem da referida exigência. Também se pode supor que a exigência de exclusividade tenha contribuído significativamente para que a intervenção setorial não atingisse seus objetivos. Com base nesses elementos é possível enunciar-se a proposição P1:

P1 - A exigência de exclusividade imposta por grandes fabricantes de calçados limitou a variedade e a inovação ofertadas pelos fabricantes de insumos e reduziu a atratividade de iniciativas setoriais.

A análise da variável Oferta revela que a maioria dos itens expostos destinava-se ao mercado casual, e não ao mercado esportivo, tradicional foco da região. De parte dos grandes e médios fornecedores de insumos, essa opção objetivava evitar conflitos com os representantes locais. Conforme apurado, essa postura reduziu a atratividade da Materioteca

Quadro 6. Síntese dos achados: fornecedores.

\begin{tabular}{|c|c|c|}
\hline Constructo & Variável & Síntese \\
\hline \multirow{3}{*}{ Insumos } & Variedade & A condição de exclusividade reduz a variedade \\
\hline & Inovação & A possibilidade de cópia inibe a exposição de inovações \\
\hline & Oferta & A possibilidade de conflito com os representantes induziu ofertas desfocadas \\
\hline \multirow{3}{*}{ Suprimentos } & Entregas & $\begin{array}{l}\text { Todos os fornecedores atendem aos pedidos da Materioteca em janelas ociosas } \\
\text { de sua capacidade produtiva }\end{array}$ \\
\hline & Alternativas & $\begin{array}{l}\text { Grandes e médios fornecedores relutam em participar em função da } \\
\text { possibilidade de conflitos com os representantes }\end{array}$ \\
\hline & Condições & $\begin{array}{l}\text { O baixo volume de venda na Materioteca se reflete em um aumento no preço } \\
\text { dos insumos à venda na Materioteca }\end{array}$ \\
\hline
\end{tabular}


para os fabricantes de calçados de todos os portes. A redução da atratividade da Materioteca, por sua vez, prejudicou os pequenos fornecedores de insumos, que buscavam prospectar novos clientes a baixo custo. Esses elementos permitem enunciar P2:

P2 - A possibilidade de conflito com representantes locais reduziu o resultado de uma intervenção setorial destinada a aumentar a flexibilidade de suprimento.

\subsection{Análise transversal: Suprimentos}

A análise dos achados da variável Entregas indica que a pouca variedade e o baixo grau de inovação geraram pequeno volume de negócios na Materioteca, reduzindo assim sua importância junto a fornecedores de insumos e fabricantes de calçados. A atratividade para os pequenos e médios calçadistas também é reduzida pelos atrasos nas entregas verificados nas compras feitas na Materioteca, independente do tamanho do fornecedor. Cumpre destacar que tal contexto não se verifica nas entregas para os grandes fabricantes. Esses elementos sugerem que os fornecedores de insumos possuem políticas diferenciadas de atendimento aos fabricantes de calçados da região. A referida política parece ser definida com base no poder de compra do fabricante de calçados. As conclusões sugerem P3:

\section{P3 - A existência de políticas de entregas diferenciadas conforme o porte do comprador reduziu o resultado de intervenções setoriais destinadas a aumentar a flexibilidade de suprimento de uma cadeia produtiva.}

Quanto à variável Alternativas, o pequeno número de grandes e médios expositores de insumos instalados na Materioteca decorre da postura de não estimular conflitos entre as empresas e seus representantes locais. Resulta em redução na atratividade da Materioteca junto aos fabricantes de calçados de todos os portes, o que reduz o número de pequenos fornecedores de insumos interessados em expor na Materioteca. Cria-se um ciclo reforçador negativo na intervenção. A análise desses elementos reforça o conteúdo de $\mathrm{P} 2$.

Os achados da variável Condições indicam que a perda de focalização da Materioteca nas grandes demandas regionais reduziu o volume de itens comercializados, o que se refletiu em aumento no preço dos insumos à venda. Cumpre destacar que esse aumento de preços somente é relatado pelos pequenos e médios fabricantes de calçados. Novamente aqui os achados do estudo sugerem que os fornecedores de insumos possuam políticas diferenciadas de atendimento aos fabricantes de calçados da região, definidas com base no poder de compra do fabricante de calçados. As conclusões sugerem P4:

\begin{abstract}
P4 - Intervenções em cadeias produtivas desfocadas das grandes demandas regionais não resultaram em redução do preço dos insumos comercializados e reduziram a atratividade de iniciativas setoriais.
\end{abstract}

Em síntese, quatro recomendações emergem da pesquisa, para futuro aproveitamento em novas intervenções setoriais em arranjos de moda rápida: (i) limitar a exigência de exclusividade imposta pelos grandes fabricantes atuantes no arranjo; (ii) prevenir, por meio de outras compensações, conflitos potenciais com representantes locais; (iii) limitar a existência de políticas de entregas diferenciadas conforme o porte do comprador; e (iv) focar as iniciativas nas demandas regionais, principalmente com objetivos específicos de redução de preço e aumento de disponibilidade de materiais, tanto em prazos como em variedade. Caso as entidades que participaram da pesquisa se interessem em produzir novas iniciativas, estas quatro sugestões podem e devem ser inseridas no planejamento das ações.

\section{Considerações finais}

O objetivo deste artigo foi entender porque a intervenção setorial realizada pela Materioteca de Nova Serrana não produziu os resultados desejados. Foram estudados quinze produtores de calçados e quinze fornecedores de insumos que participaram da concepção e implantação da intervenção. Os achados sugerem que a demanda por exclusividade pelos grandes fabricantes de calçados, a possibilidade de conflito com os representantes dos grandes e médios fornecedores de insumos, o receio de cópia das criações, a não focalização nas maiores demandas locais e o desempenho insatisfatório em entregas reduziu o resultado da intervenção. A pesquisa gerou quatro sugestões que podem e devem ser atendidas, caso novas iniciativas do gênero sejam planejadas.

A pesquisa teve relevância empresarial, pois que seus resultados podem fornecer subsídios a gestores setoriais, empresariais e públicos interessados em desenvolver ações articuladas por diferentes atores da cadeia produtiva. Também teve relevância científica, pois, até onde se pesquisou, este foi o primeiro estudo de caso envolvendo a análise das barreiras que bloquearam o sucesso de uma intervenção setorial articulada por diferentes agentes de uma cadeia produtiva. A pesquisa teve limitações. Os estudos de caso se concentraram apenas nos fabricantes de calçados e fornecedores de insumos para a indústria de fast fashion, atuantes na região de Nova Serrana. Não é prudente generalizar os achados para outros contextos.

Para superar as limitações da presente pesquisa, as proposições derivadas dos estudos de caso deverão, na sequência, ser desdobradas e dar origem a conjuntos 
de questões que farão parte de survey a ser submetido à mesma indústria. A partir das respostas, por métodos de análise multivariada, conclusões mais abrangentes do que as deste estudo poderão ser obtidas e estendidas a outros setores da indústria.

\section{Referências}

ABECASSIS-MOEDAS, C. Integrating design and retail in the clothing value chain: an empirical study of the organization of design. International Journal of Operations \& Production Management, v. 26, n. 4 , p. 412-428, 2006. http://dx.doi. org/10.1108/01443570610650567

AVITTATHUR, B.; SWAMIDASS, P. Matching plant flexibility and supplier flexibility: lessons from small suppliers of US manufacturing plants in India. Journal of Operations Management, v. 25, n. 3, p. 717-35, 2007. http://dx.doi.org/10.1016/j.jom.2006.05.015

BAKER, M. Selecting a research methodology. The Marketing Review, v. 1, n. 3, p. 373-397, 2001. http:// dx.doi.org/10.1362/1469347002530736

BARRATT, M.; CHOI, T.; LI, M. Qualitative case studies in operations management: Trends, research outcomes, and future research implications. Journal of Operations Management, v. 29, n. 4, p. 329-342, 2011. http:// dx.doi.org/10.1016/j.jom.2010.06.002

BENBASAT, I.; GOLDSTEIN, D.; MEAD, M. The case research strategy in studies of information systems. MIS Quarterly, v. 11, n. 3, p. 369-86, 1987. http:// dx.doi.org/10.2307/248684

BHATNAGAR, R.; SOHAL, A. Supply chain competitiveness: measuring the impact of location factors, uncertainty and manufacturing practices. Technovation, v. 25 , n. 5, p. 443-56, 2005. http://dx.doi.org/10.1016/j. technovation.2003.09.012

BLACKHURTS, J.; WU, T.; O'GRADY, P. PCDM: a decision support modeling methodology for supply chain, product and process design decision. Journal of Operations Management, v. 23, n. 3-4, p. 325-43, 2005. http://dx.doi.org/10.1016/j.jom.2004.05.009

BOULAKSIL, Y.; FRANSOO, J. Implications of outsourcing on operations planning: findings from the pharmaceutical industry. International Journal of Operations \& Production Management, v. 30, n. 10, p. 1059-1079, 2010. http://dx.doi.org/10.1108/01443571011082526

BRUN, A.; CAPRA, E.; MIRAGLIOTTA, G. Behavioural costs in manufacturing: how to balance standardization and variety costs. In: INTERNATIONAL WORKING SEMINAR ON PRODUCTION ECONOMICS, 14., 2006, Innsbruck, Austria. Proceedings...

BUDDRESS, L. Managing supply chain sustainability and risk: Keys to success. Strategic Management, v. 18, n. 2, p. 3-16, 2013.

CARO, F.; GALLIEN, J. Clearance pricing optimization for a fast-fashion retailer. Operations Research, v. 60, n. 6, p. 1404-1422, 2012. http://dx.doi.org/10.1287/ opre. 1120.1102

CHAN, H.; CHAN, F. Comparative study of adaptability and flexibility in distributed manufacturing supply chains.
Decision Support Systems, v. 48, n. 2, p. 331-341, 2010. http://dx.doi.org/10.1016/j.dss.2009.09.001

CHILDERHOUSE, P.; AITKEN, J.; TOWILL, D. Analysis and design of focused supply chain. Journal of Operations Management, v. 20, n. 6, p. 675-89, 2002. http://dx.doi.org/10.1016/S0272-6963(02)00034-7

CHILDERHOUSE, P.; TOWILL, D. Reducing uncertainty in European supply chains. Journal of Manufacturing Technology Management, v. 15, n. 7, p. 585-98, 2004. http://dx.doi.org/10.1108/17410380410555835

CHRISTOPHER, M.; HOLWEG, M. Supply Chain 2.0: managing supply chains in the era of turbulence. International Journal of Physical Distribution \& Logistics Management, v. 41, n. 1, p. 63-82, 2011. http://dx.doi.org/10.1108/09600031111101439

CHRISTOPHER, M.; LOWSON, R.; PECK, H. Creating agile supply chain in the fashion industry. International Journal of Retail \& Distribution Management, v. 32, n. 8, p. 367-76, 2004. http://dx.doi. org/10.1108/09590550410546188

CROCCO, M. et al. Industrialização descentralizada: sistemas industriais locais: o arranjo produtivo calçadista de Nova Serrana (MG). Parcerias Estratégicas, v. 8, n. 17 , p. $55-134,2010$.

DAS, A. Towards theory building in manufacturing flexibility. International Journal of Production Research, v. 39, n. 18, p. 4153-4177, 2001. http:// dx.doi.org/10.1080/00207540110072281

DAS, S.; ABDEL-MALEK, L. Modelling the flexibility of order quantities and lead-times in supply chains. International Journal of Production Economics, v. 85, n. 2, p. 171-181, 2003. http://dx.doi.org/10.1016/ S0925-5273(03)00108-7

DORAN, D. et al. Supply chain modularisation: cases from the French automobile industry. International Journal of Production Economics, v. 106, n. 1, p. 2-11, 2007. http://dx.doi.org/10.1016/j.ijpe.2006.04.006

DUBOIS, A.; GADDE, L. E. Systematic combining: an abductive approach to case research. Journal of Business Research, v. 55, n. 5, p. 553-560, 2002. http://dx.doi. org/10.1016/S0148-2963(00)00195-8

DUCLOS, L.; VOKURKA, R.; LUMMUS, R. A conceptual model of supply chain management. Industrial Management \& Data Systems, v. 103, n. 5-6, p. 446-56, 2003. http://dx.doi.org/10.1108/02635570310480015

EBBEN, J.; JOHNSON, A. Efficiency, flexibility, or both? Evidence linking strategy to performance in small firms. Strategic Management Journal, v. 26, n. 13, p. 1249-59, 2005. http://dx.doi.org/10.1002/smj.503

EISENHARDT, K. Building theory from case study research. Academy of Management Review, v. 14, n. 4, p. 532-50, 1989.

EISENHARDT, K.; GRAEBNER, M. Theory building from cases: opportunities and challenges, Academy of Management Journal, v. 50, n. 1, p. 25-32, 2007. http://dx.doi.org/10.5465/AMJ.2007.24160888

ENOQUE, A.; PIMENTA, S. A fábrica e a casa: configurações do trabalho na indústria calçadista de Nova Serrana/MG. Revista de Administração FEAD, v. 2, n. 1, p. 55-72, 2010. 
FANTAZY, K.; KUMAR, V.; KUMAR, U. An empirical study of the relationships among strategy, flexibility, and performance in the supply chain context. Supply Chain Management, v.14, n. 3, p. 177-188, 2009. http:// dx.doi.org/10.1108/13598540910954520

FAWCETT, S.; CALANTONE, R.; SMITH, S. An investigation of the impact of flexibility on global reach and firm performance. Journal of Business Logistics, v. 17, n. 2, p. 167-96, 1996.

FEITZINGER, E.; LEE, H. Mass customization at Hewlett Packard: the power of postponement. Harvard Business Review, v. 75, n. 1, p. 116-121, 1997.

FERNANDES, F. et al. Proposta de um método para atingir a manufatura responsiva na indústria de calçados: implantação e avaliação por meio de uma pesquisa-ação. Gestão \& Produção, v. 19, n. 3, p. 509-529, 2012. http://dx.doi.org/10.1590/S0104-530X2012000300006

FINE, C. Clockspeed: winning industry control in the age of temporary advantage. New York: Perseus Books, 1998.

FISHER, M. What is the right supply chain for your product? Harvard Business Review, p. 105-116, 1997.

FISHER, M.; ITTNER, C. The impact of product variety on automobile assembly operations: empirical evidence and simulation analysis. Management Science, v. 45, n. 6, p. 771-86, 1999. http://dx.doi.org/10.1287/mnsc.45.6.771

FIXSON, S. Product architecture assessment: a tool to link product, process and supply chain decisions. Journal of Operations Management, v. 23, n. 3-4, p. 345-69, 2005. http://dx.doi.org/10.1016/j.jom.2004.08.006

GERWIN, D. Manufacturing flexibility: a strategic perspective. Management Science, v. 39, n. 4, p. 395-410, 1993. http://dx.doi.org/10.1287/mnsc.39.4.395

GLASER, B.; STRAUSS, A. Discovery of grounded theory. Chicago: Aldine, 1967. PMCid:PMC224645

GOETZ, J.; LECOMPTE, M. Ethnography and qualitative design in educational research. Orlando: Academic Press, 1984.

GOODWIN, L.; GOODWIN, W. Are validity and reliability "relevant" in qualitative evaluation research? Evaluation \& the health professions, v. 7, n. 4, p. 413-426, 1984. PMid:10269328. http://dx.doi. org/10.1177/016327878400700403

GOSLING, J.; PURVIS, L.; NAIM, M. Supply chain flexibility as a determinant of supplier selection. International Journal of Production Economics, v. 128, n. 1, p. 11-21, 2010. http://dx.doi.org/10.1016/j. ijpe.2009.08.029

HANDFIELD, R.; MELNYK, S. The scientific theorybuilding process: a primer using the case of TQM. Journal of Operations Management, v. 16, n. 3, p. 321-39, 1998. http://dx.doi.org/10.1016/S0272-6963(98)00017-5

HO, C.; CHI, Y.; TAI, Y. A structural approach to measuring uncertainty in supply chains. International Journal of Electronic Commerce, v. 9, n. 3, p. 91-114, 2005.

HOLMSTRÖM, J. et al. Managing product introductions across the supply chain: findings from a development project. Supply Chain Management: An International Journal, v. 11, n. 2, p. 121-30, 2006. http://dx.doi. org/10.1108/13598540610652519

HUANG, G.; ZHANG, X.; LIANG, L. Towards integrated optimal configuration of platform products, manufacturing processes, and supply chains. Journal of Operations Management, v. 23, n. 3-4, p. 267-90, 2005. http:// dx.doi.org/10.1016/j.jom.2004.10.014

HUANG, S.; UPPAL, M.; SHI, J. A product-driven approach to manufacturing supply chain selection. Supply Chain Management: An International Journal, v. 7, n. 4, p. 189-99, 2002. http://dx.doi. org/10.1108/13598540210438935

HULT, G.; SWAN, K. A research agenda for the nexus of product development and supply chain management processes. Journal of Product Innovation Management, v. 20, n. 6, p. 333-336, 2003. http:// dx.doi.org/10.1111/1540-5885.00039

JICK, T. Mixing qualitative and quantitative methods: triangulation in action. Administrative Science Quarterly, v. 24, n. 4, p. 602-611, 1979. http://dx.doi. org/10.2307/2392366

KETOKIVI, M. Elaborating the contingency theory of organizations: the case of manufacturing flexibility strategies. Production and Operations Management, v. 15, n. 2, p. 215-28, 2006. http://dx.doi. org/10.1111/j.1937-5956.2006.tb00241.x

KOSTE, L. Measurement of manufacturing flexibility and its implications for supply chain management. Thesis (Ph.D.)-University of South Carolina, Colombia, 1999.

KRISHNAN, V.; ULRICH, K. Product development decisions: a review of the literature. Management Science, v. 47, n. 1, p. 1-21, 2001.

KUMAR, A.; FANTAZY, K.; KUMAR, U. Implementation and management framework for supply chain flexibility. Journal of Enterprise Information, v. 19, n. 3, p. 303-319, 2006. http://dx.doi. org/10.1108/17410390610658487

LAU, A.; YAM, R. A case study of product modularization on supply chain design and coordination in Hong Kong and China. Journal of Manufacturing Technology Management, v. 16, n. 4, p. 432-46, 2005. http://dx.doi. org/10.1108/17410380510594516

LAU, R. Strategic flexibility: a new reality for world-class manufacturing. SAM Advanced Management Journal, v. 61, n. 1, p. 11-15, 1996.

LEE, H. Aligning supply chain strategies with product uncertainties. California Management Review, v. 44, n. 3, p. 105-119, 2002. http://dx.doi. org/10.2307/41166135

LEE, H.; SASSER, M. Product universality and design for supply chain. Production Planning and Control, v. 6, n. 3, p. 270-277, 1995. http://dx.doi. org/10.1080/09537289508930279

LOCKAMY, A.; McCORMACK, K. Analysing risks in supply networks to facilitate outsourcing decisions. International Journal of Production Research, v. 48, n. 2, p. 593-611, 2010. http://dx.doi. org/10.1080/00207540903175152

LOMBARDI, M.; BRITO, E. Incerteza subjetiva no processo de decisão estratégica: uma proposta de mensuração. Revista de Administração Contemporânea, v. 14, n. 6, p. 990-1010, 2010. http://dx.doi.org/10.1590/ S1415-65552010000700002 
LUMMUS, R.; DUCLOS, L.; VOKURKA, R. Supply chain flexibility: building a new model. Global Journal of Flexible Systems Management, v. 4, n. 4, p. 1-13, 2003.

MACDUFFIE, J.; SETHURAMAN, K.; FISHER, M. Product variety and manufacturing performance: evidence from the international automotive assembly plant study. Management Science, v. 42, n. 3, p. 350-369, 1996. http://dx.doi.org/10.1287/mnsc.42.3.350

MEREDITH, J. Building operations management theory through case and field research. Journal of Operations Management, v. 16, n. 4, p. 441-454, 1998. http:// dx.doi.org/10.1016/S0272-6963(98)00023-0

MILLER, J.; VOLLMANN, T. The hidden factory. Harvard Business Review, v. 63, n. 5, p. 142-150, 1985.

MO, Y. A robust supply chain design under demand uncertainty and hybrid postponement strategies: issues in supply chain management. Thesis (Ph.D.)Pennsylvania State University, University Park, 2002.

NARASIMHAN, R.; DAS, A. An empirical examination of sourcing's role in developing manufacturing flexibilities. International Journal of Production Research, v. 38, n. 4, p. 875-893, 2000. http://dx.doi. org/10.1080/002075400189202

NARASIMHAN, R.; DAS, A. Manufacturing agility and supply chain management practices. Production \& Inventory Management Journal, v. 40, n. 1, p. 4-10, 1999.

NOVAK, S.; EPPINGER, S. Sourcing by design: product complexity and the supply chain. Management Science, v. 47, n. 1, p. 189-204, 2001. http://dx.doi.org/10.1287/ mnsc.47.1.189.10662

OLHAGER, J.; WEST, B. The house of flexibility: using the QFD approach to deploy manufacturing flexibility. International Journal of Operations \& Production Management, v. 22, n. 1, p. 50-79, 2002. http://dx.doi. org/10.1108/01443570210412079

OLIVA, R.; WATSON, N. Cross-functional alignment in supply chain planning: A case study of sales and operations planning. Journal of Operations Management, v. 29, n. 5, p. 434-448, 2011. http:// dx.doi.org/10.1016/j.jom.2010.11.012

PAULRAJ, A.; CHEN, I. Environmental uncertainty and strategic supply management: a resource dependence perspective and performance implications. The Journal of Supply Chain Management, v. 43, n. 3, p. 29-42, 2007. http://dx.doi.org/10.1111/j.1745-493X.2007.00033.x

PERO, M. et al. A framework for the alignment of new product development and supply chains. Supply Chain Management: An International Journal, v. 15, n. 2, p. 115-128, 2010. http://dx.doi. org/10.1108/13598541011028723

PIRES, S.; SACOMANO NETO, M. Características estruturais, relacionais e gerenciais na cadeia de suprimentos de um condomínio industrial na indústria automobilística. Produção, v. 20, n. 2, p. 172-185, 2010. http://dx.doi.org/10.1590/S0103-65132010005000032

PUJAWAN, I. N. Schedule nervousness in a manufacturing system: a case study. Production Planning and Control, v. 15, n. 5, p. 515-524, 2004. http://dx.doi.org/10.1080 $/ 09537280410001726320$
QI, L.; SHEN, Z; SNYDER, L. The effect of supply disruptions on supply chain design decisions. Transportation Science, v. 44, n. 2, p. 274-289, 2010. http://dx.doi.org/10.1287/trsc.1100.0320

RO, Y.; LIKER, J.; FIXON, S. Modularity as a strategy for supply chain coordination: the case of US Auto. IEEE Transactions on Engineering Management, v. 54, n. 1, p. 172-189, 2007. http://dx.doi.org/10.1109/ TEM.2006.889075

RODRIGUES, D.; SELLITTO, M. Práticas logísticas colaborativas: o caso de uma cadeia de suprimentos da indústria automobilística. Revista de Administração da Universidade de São Paulo, v. 43, n. 1, p. 97-11, 2008.

RUNGTUSANATHAM, M.; FORZA, C. Coordinating product design, process design, and supply chain design decisions. Journal of Operations Management, v. 23, n. 3, p. 257-60, 2005. http://dx.doi.org/10.1016/j. jom.2004.10.013

SALVADOR, F.; FORZA, C.; RUNGTUSANATHAM, M. Modularity, product variety, production volume, and component sourcing: theorizing beyond generic prescriptions. Journal of Operations Management, v. 20, n. 5, p. 549-575, 2002. http://dx.doi.org/10.1016/ S0272-6963(02)00027-X

SÁNCHEZ, A.; PÉREZ, M. Supply chain flexibility and firm performance: a conceptual model and empirical study in the automotive industry. International Journal of Operations \& Production Management, v. 25, n. 7, p. 681-700, 2005. http:// dx.doi.org/10.1108/01443570510605090

SANCHEZ, R.; MAHONEY, J. Modularity, flexibility and knowledge management in product and organization design. Strategic Management Journal, v. 17, n. S2, p. 63-76, 1996. http://dx.doi.org/10.1002/smj.4250171107 SANTOS, H.; ROMEIRO FILHO, E. Processos de produção e trabalho no Arranjo Produtivo Local calçadista de Nova Serrana. Gestão da Produção, Operações e Sistemas, v. 8, n. 2, p. 55-65, 2013.

SAWHNEY, R. Interplay between uncertainty and flexibility across the value-chain: towards a transformation model of manufacturing flexibility. Journal of Operations Management, v. 24, n. 5, p. 476-493, 2006. http:// dx.doi.org/10.1016/j.jom.2005.11.008

SCHILLING, M.; STEENSMA, H. The use of modular organizational forms: an industry-level analysis. Academy of Management Journal, v. 44, n. 6, p. 114968, 2001. http://dx.doi.org/10.2307/3069394

SCHOLZ, R.; TIETJE, O. Embedded case study methods: integrating quantitative and qualitative knowledge. Thousand Oaks: Sage, 2002.

SELLITTO, M. et al. Relative complexity measurement of a supply chain based on information theory. In: THE INTERNATIONAL MULTI-CONFERENCE ON COMPLEXITY, INFORMATICS AND CYBERNETICS - IMCIC, 2010, Orlando. Proceedings... Orlando, 2010.

SILVA, F.; FERNANDES, F. Proposta de um sistema de controle da produção para fabricantes de calçados que operam sob encomenda. Gestão \& Produção, v. 15, n. 3, p. 523-538, 2008. 
SIMCHI-LEVI, D.; KAMINSKY, P.; SIMCHI-LEVI, E. Designing and managing the supply chain. Boston: McGraw-Hill, 2002.

SODHI, M.; SON, B; TANG, C. Researchers' perspectives on supply chain risk management. Production and Operations Management, v. 21, n. 1, p. 1-13, 2012. http://dx.doi.org/10.1111/j.1937-5956.2011.01251.x

STEVENSON, M.; SPRING, M. Flexibility from a supply chain perspective: definition and review. International Journal of Operations \& Production Management, v. 29, n. 9, p. 946-971, 2009. http:// dx.doi.org/10.1108/01443570910986238

STEVENSON, M.; SPRING, M. Supply chain flexibility: an inter-firm empirical study. International Journal of Operations \& Production Management, v. 27, n. 7, p. 685-713, 2007. http://dx.doi. org/10.1108/01443570710756956

STRAUSS, A.; CORBIN, J. Basics of qualitative research: techniques and procedures for developing grounded theory. Thousand Oaks: Sage, 1998.

STURGEON, T. Modular production networks: a new American model of industrial organization. Industrial and Corporate Change, v. 11, n. 3, p. 451-496, 2002. http://dx.doi.org/10.1093/icc/11.3.451

SUZIGAN, W. et al. A indústria de calçados de Nova Serrana (MG). Nova economia, v. 15, n. 3, p. 97-116, 2005. http://dx.doi.org/10.1590/S0103-63512005000300004

TANG, O.; MUSA, S. Identifying risk issues and research advancements in supply chain risk management. International Journal of Production Economics, v. 133, n. 1, p. 25-34, 2011. http://dx.doi.org/10.1016/j. ijpe.2010.06.013

THUN, J.; HOENIG, D. An empirical analysis of supply chain risk management in the German automotive industry. International Journal of Production Economics, v. 131, n. 1, p. 242-249, 2011. http:// dx.doi.org/10.1016/j.ijpe.2009.10.010

TUNCEL, G.; ALPAN, G. Risk assessment and management for supply chain networks: a case study. Computers in Industry, v. 61, n. 3, p. 250-259, 2010. http://dx.doi. org/10.1016/j.compind.2009.09.008
ULRICH, K. The role of product architecture in the manufacturing firm. Research Policy, v. 24, n. 3, p. 419-440 1995. http://dx.doi. org/10.1016/0048-7333(94)00775-3

VAN DER VORST, J.; BEULENS, A. Identifying sources of uncertainty to generate supply chain redesign strategies. International Journal of Physical Distribution \& Logistics Management, v. 32, n. 6, p. 409-430, 2002. http://dx.doi.org/10.1108/09600030210437951

VASCONCELOS, G.; OLIVEIRA, J. Imersão social e institucional e capacidades: o setor calçadista de Nova Serrana. Revista de Administração de Empresas, v. 52, n. 5, p. 531-545, 2012. http://dx.doi.org/10.1590/ S0034-75902012000500005

VICKERY, S.; CALANTONE, R.; DRÖGE, C. Supply chain flexibility: an empirical study. Journal of Supply Chain Management, v. 35, n. 3, p. 16-24, 1999. http:// dx.doi.org/10.1111/j.1745-493X.1999.tb00058.x

VONDEREMBSE, M. et al. Designing supply chains: towards theory development. International Journal of Production Economics, v. 100, n. 2, p. 223-38, 2006. http://dx.doi.org/10.1016/j.ijpe.2004.11.014

VOSS, C.; TSIKRIKTSIS, N.; FROHLICH, M. Case research in operations management. International Journal of Operations \& Production Management, v. 22, n. 2, p. 195-219, 2002. http://dx.doi. org/10.1108/01443570210414329

WAGNER, S.; BODE, C. An empirical examination of supply chain performance along several dimensions of risk. Journal of Business Logistics, v. 29, n. 1, p. 307-325, 2008. http://dx.doi.org/10.1002/j.2158-1592.2008. tb00081.X

YIN, R. Case study research: design and methods. Thousand Oaks: Sage, 2009.

ZHANG, Q.; VONDEREMBSE, M.; LIM, J. Spanning flexibility: supply chain information dissemination drives strategy development and customer satisfaction. Supply Chain Management: An International Journal, v. 11, n. 5, p. 390-399, 2006. http://dx.doi. org/10.1108/13598540610682408 
Apêndice I. Constructo Insumos: Fabricantes.

\begin{tabular}{|c|c|c|c|c|c|c|c|c|c|c|c|c|c|c|c|c|}
\hline \multirow[b]{2}{*}{ VARIÁVEL } & \multirow{2}{*}{$\begin{array}{l}\text { ACHADOS } \\
\text { CODIFICADOS }\end{array}$} & \multicolumn{5}{|c|}{ GRANDES } & \multicolumn{5}{|c|}{ MÉDIOS } & \multicolumn{5}{|c|}{ PEQUENOS } \\
\hline & & $\begin{array}{l}\mathbf{C} \\
\mathbf{1} \\
\end{array}$ & $\begin{array}{l}\mathrm{C} \\
\mathbf{2} \\
\end{array}$ & $\begin{array}{l}\mathbf{C} \\
\mathbf{3} \\
\end{array}$ & $\begin{array}{l}\mathrm{C} \\
4 \\
\end{array}$ & $\begin{array}{l}\mathrm{C} \\
\mathbf{5} \\
\end{array}$ & $\begin{array}{l}\mathrm{C} \\
6 \\
\end{array}$ & $\begin{array}{l}\mathrm{C} \\
7 \\
\end{array}$ & $\begin{array}{l}\mathrm{C} \\
8 \\
\end{array}$ & $\begin{array}{l}\mathrm{C} \\
\mathbf{9} \\
\end{array}$ & $\begin{array}{c}\mathrm{C} \\
10\end{array}$ & $\begin{array}{c}\mathrm{C} \\
11 \\
\end{array}$ & $\begin{array}{c}C \\
12 \\
\end{array}$ & $\begin{array}{c}\mathrm{C} \\
13 \\
\end{array}$ & $\begin{array}{c}\mathrm{C} \\
14 \\
\end{array}$ & $\begin{array}{l}\mathrm{C} \\
15 \\
\end{array}$ \\
\hline \multirow[b]{2}{*}{ Variedade } & $\begin{array}{l}\text { Pequena em } \\
\text { relação à } \\
\text { oferta dos } \\
\text { representantes }\end{array}$ & $\mathrm{X}$ & $\mathrm{X}$ & $X$ & $X$ & $X$ & & & & & & & & & & \\
\hline & $\begin{array}{l}\text { Pequena, } \\
\text { mas essencial } \\
\text { para quem } \\
\text { recebe poucos } \\
\text { vendedores }\end{array}$ & & & & & & $X$ & $X$ & $X$ & $\mathrm{X}$ & $\mathrm{X}$ & $\mathrm{X}$ & $\mathrm{X}$ & $\mathrm{X}$ & $\mathrm{X}$ & $\mathrm{X}$ \\
\hline \multirow[b]{2}{*}{ Inovação } & $\begin{array}{c}\text { Baixo índice de } \\
\text { novidades da } \\
\text { estação }\end{array}$ & $\mathrm{X}$ & $\mathrm{X}$ & $\mathrm{X}$ & $\mathrm{X}$ & $X$ & & & & & & & & & & \\
\hline & $\begin{array}{l}\text { Alguns insumos } \\
\text { interessam para } \\
\text { a atuação em } \\
\text { nichos }\end{array}$ & & & & & & $X$ & $X$ & $X$ & $\mathrm{X}$ & $\mathrm{X}$ & $\mathrm{X}$ & $X$ & $\mathrm{X}$ & $X$ & $\mathrm{X}$ \\
\hline Oferta & $\begin{array}{l}\text { Muitos itens para } \\
\text { calçado do tipo } \\
\text { casual ao invés } \\
\text { do esportivo }\end{array}$ & $\mathrm{X}$ & $X$ & $X$ & $\mathrm{X}$ & $X$ & $X$ & $X$ & $X$ & $\mathrm{X}$ & $\mathrm{X}$ & $\mathrm{X}$ & $X$ & $\mathrm{X}$ & $X$ & $\mathrm{X}$ \\
\hline
\end{tabular}

Apêndice II. Constructo Suprimento: Fabricantes.

\begin{tabular}{|c|c|c|c|c|c|c|c|c|c|c|c|c|c|c|c|c|}
\hline \multirow[b]{2}{*}{ VARIÁVEL } & \multirow{2}{*}{$\begin{array}{c}\text { ACHADOS } \\
\text { CODIFICADOS }\end{array}$} & \multicolumn{5}{|c|}{ GRANDES } & \multicolumn{5}{|c|}{ MÉDIOS } & \multicolumn{5}{|c|}{ PEQUENOS } \\
\hline & & $\begin{array}{l}\mathrm{C} \\
\mathbf{1} \\
\end{array}$ & $\begin{array}{l}\mathbf{C} \\
\mathbf{2} \\
\end{array}$ & $\begin{array}{l}\mathbf{C} \\
\mathbf{3} \\
\end{array}$ & $\begin{array}{l}\mathrm{C} \\
4 \\
\end{array}$ & $\begin{array}{l}\mathbf{C} \\
\mathbf{5}\end{array}$ & $\begin{array}{l}\mathrm{C} \\
6 \\
\end{array}$ & $\begin{array}{l}\mathrm{C} \\
7 \\
\end{array}$ & $\begin{array}{l}\mathrm{C} \\
\mathbf{8} \\
\end{array}$ & $\begin{array}{l}\mathrm{C} \\
9 \\
\end{array}$ & $\begin{array}{c}\mathrm{C} \\
\mathbf{1 0} \\
\end{array}$ & $\begin{array}{c}\mathrm{C} \\
11 \\
\end{array}$ & $\begin{array}{c}\mathrm{C} \\
12 \\
\end{array}$ & $\begin{array}{c}\mathrm{C} \\
13 \\
\end{array}$ & $\begin{array}{c}\mathrm{C} \\
14 \\
\end{array}$ & $\begin{array}{l}\mathrm{C} \\
15 \\
\end{array}$ \\
\hline \multirow[b]{2}{*}{ Entregas } & \begin{tabular}{|c|} 
Todas as encomendas \\
foram entregues no \\
prazo acordado
\end{tabular} & $\mathrm{X}$ & $\mathrm{X}$ & $X$ & $\mathrm{X}$ & $\mathrm{X}$ & & & & & & & & & & \\
\hline & \begin{tabular}{|c|} 
As encomendas \\
feitas na Materioteca \\
foram entregues \\
fora do prazo \\
\end{tabular} & & & & & & $X$ & $X$ & $X$ & $X$ & $X$ & $X$ & $X$ & $\mathrm{X}$ & $X$ & $X$ \\
\hline Alternativas & $\begin{array}{c}\text { Poucos fornecedores } \\
\text { de insumos por tipo } \\
\text { de produto exposto }\end{array}$ & $X$ & $\mathrm{X}$ & $\mathrm{X}$ & $X$ & $\mathrm{X}$ & $\mathrm{X}$ & $\mathrm{X}$ & $X$ & $X$ & $\mathrm{X}$ & $X$ & $X$ & $\mathrm{X}$ & $\mathrm{X}$ & $\mathrm{X}$ \\
\hline \multirow[b]{2}{*}{ Condições } & $\begin{array}{l}\text { Apesar de maiores, } \\
\text { os preços condizem } \\
\text { com o exposto }\end{array}$ & $\mathrm{X}$ & $X$ & $X$ & $\mathrm{X}$ & $X$ & & & & & & & & & & \\
\hline & $\begin{array}{l}\text { Preço dos insumos } \\
\text { fora do perfil de } \\
\text { produto produzido } \\
\text { da região }\end{array}$ & & & & & & $\mathrm{X}$ & $X$ & $X$ & $X$ & $X$ & $X$ & $\mathrm{X}$ & $X$ & $X$ & $\mathrm{X}$ \\
\hline
\end{tabular}


Apêndice III. Constructo Insumos: Fornecedores.

\begin{tabular}{|c|c|c|c|c|c|c|c|c|c|c|c|c|c|c|c|c|}
\hline \multirow{2}{*}{ VARIÁVEL } & \multirow{2}{*}{$\begin{array}{c}\text { ACHADOS } \\
\text { CODIFICADOS } \\
\end{array}$} & \multicolumn{5}{|c|}{ GRANDES } & \multicolumn{5}{|c|}{ MÉDIOS } & \multicolumn{5}{|c|}{ PEQUENOS } \\
\hline & & I1 & I2 & I3 & I4 & I5 & I6 & I7 & I8 & I9 & I10 & I11 & I12 & I13 & I14 & I15 \\
\hline \multirow[t]{2}{*}{ Variedade } & $\begin{array}{c}\text { Contratos de } \\
\text { exclusividade } \\
\text { (usualmente } 6 \\
\text { meses) limitam a } \\
\text { variedade exposta } \\
\end{array}$ & $\mathrm{X}$ & $\mathrm{X}$ & $\mathrm{X}$ & $\mathrm{X}$ & $X$ & $\mathrm{X}$ & $X$ & $X$ & $\mathrm{X}$ & $\mathrm{X}$ & $X$ & $\mathrm{X}$ & $X$ & $\mathrm{X}$ & $X$ \\
\hline & $\begin{array}{c}\text { Pouca estrutura } \\
\text { para gerenciar o } \\
\text { conteúdo exposto } \\
\text { na Materioteca } \\
\end{array}$ & & & & & & & & & & & $X$ & $X$ & $X$ & $\mathrm{X}$ & $X$ \\
\hline Inovação & \begin{tabular}{|c|} 
Receio de cópia \\
e baixos volumes \\
restringem a \\
divulgação de \\
novidades \\
\end{tabular} & $X$ & $X$ & $\mathrm{X}$ & $\mathrm{X}$ & $\mathrm{X}$ & $X$ & $\mathrm{X}$ & $\mathrm{X}$ & $\mathrm{X}$ & $\mathrm{X}$ & $\mathrm{X}$ & $\mathrm{X}$ & $X$ & $\mathrm{X}$ & $\mathrm{X}$ \\
\hline \multirow[t]{2}{*}{ Oferta } & $\begin{array}{c}\text { A oferta de } \\
\text { insumos para } \\
\text { produtos do } \\
\text { tipo casual } \\
\text { objetiva evitar } \\
\text { conflito com } \\
\text { representantes do } \\
\text { esportivo } \\
\end{array}$ & $X$ & $\mathrm{X}$ & $X$ & $X$ & $X$ & $X$ & $X$ & $X$ & $\mathrm{X}$ & $\mathrm{X}$ & & & & & \\
\hline & $\begin{array}{c}\text { Pequenas } \\
\text { empresas } \\
\text { objetivam abrir } \\
\text { mercado para } \\
\text { insumos do tipo } \\
\text { casual } \\
\end{array}$ & & & & & & & & & & & $\mathrm{X}$ & $\mathrm{X}$ & $\mathrm{X}$ & $X$ & $X$ \\
\hline
\end{tabular}

Apêndice IV. Constructo Suprimento: Fornecedores.

\begin{tabular}{|c|c|c|c|c|c|c|c|c|c|c|c|c|c|c|c|c|}
\hline \multirow{2}{*}{ VARIÁVEL } & \multirow{2}{*}{$\begin{array}{c}\text { ACHADOS } \\
\text { CODIFICADOS }\end{array}$} & \multicolumn{5}{|c|}{ GRANDES } & \multicolumn{5}{|c|}{ MÉDIOS } & \multicolumn{5}{|c|}{ PEQUENOS } \\
\hline & & I1 & I2 & I3 & I4 & I5 & I6 & I7 & I8 & I9 & I10 & I11 & I12 & I13 & I14 & I15 \\
\hline \multirow[t]{2}{*}{ Entregas } & $\begin{array}{c}\text { A produção de } \\
\text { pequenos pedidos } \\
\text { é feita somente em } \\
\text { períodos ociosos da } \\
\text { fábrica }\end{array}$ & $\mathrm{X}$ & & & & & & & & & & & & & & \\
\hline & $\begin{array}{l}\text { Pouca estrutura para } \\
\text { atender pedidos não } \\
\text { exclusivos }\end{array}$ & & & & & & & & & & & $\mathrm{X}$ & $\mathrm{X}$ & $\mathrm{X}$ & $\mathrm{X}$ & $X$ \\
\hline \multirow{2}{*}{ Alternativas } & $\begin{array}{c}\text { As empresas não } \\
\text { desejam conflito com } \\
\text { os representantes da } \\
\text { região }\end{array}$ & $\mathrm{X}$ & $X$ & $\mathrm{X}$ & $\mathrm{X}$ & $\mathrm{X}$ & $X$ & $\mathrm{X}$ & $X$ & $X$ & $\mathrm{X}$ & & & & & \\
\hline & $\begin{array}{c}\text { A falta de estrutura } \\
\text { para mapear } \\
\text { oportunidades afasta } \\
\text { a pequena empresa }\end{array}$ & & & & & & & & & & & $\mathrm{X}$ & $\mathrm{X}$ & $\mathrm{X}$ & $\mathrm{X}$ & $\mathrm{X}$ \\
\hline Condiç̧̃es & $\begin{array}{l}\text { O baixo volume } \\
\text { de vendas da } \\
\text { Materioteca resulta } \\
\text { em aumento no } \\
\text { preço dos itens } \\
\text { comercializados. }\end{array}$ & $\mathrm{X}$ & $X$ & $\mathrm{X}$ & $\mathrm{X}$ & $X$ & $\mathrm{X}$ & $\mathrm{X}$ & $X$ & $X$ & $\mathrm{X}$ & $\mathrm{X}$ & $\mathrm{X}$ & $\mathrm{X}$ & $\mathrm{X}$ & $\mathrm{X}$ \\
\hline
\end{tabular}

